\title{
CAPSULE COMMENTARIES \\ Capsule Commentary on Powell et al., Rates and Correlates of Potentially Inappropriate Colorectal Cancer Screening in the Veterans Health Administration
}

\author{
David L. Hahn, MD MS \\ Health, Madison, WI, USA. \\ J Gen Intern Med 30(6):832 \\ DOI: $10.1007 / \mathrm{s} 11606-015-3183-\mathrm{Z}$ \\ c) Society of General Internal Medicine 2015
}

Wisconsin Research and Education Network (WREN), Department of Family Medicine, University of Wisconsin School of Medicine and Public

\begin{abstract}
A $\mathrm{n}$ inescapable fact of all cancer screening is that (of those undergoing screening) vastly more people will be harmed than helped. The key question then becomes: What are the qualities of the harms? For colon cancer screening, the United States Preventive Services Task Force (USPSTF) has determined that on a population basis, the quantity and quality of benefits for the $3 \%$ outweigh the harms for the $97 \%$ of asymptomatic adults aged 50-75 years (A Grade recommendation). ${ }^{1}$ On an individual basis, a colleague nearly died after suffering a pulmonary embolus during treatment of a perforation caused during a negative screening colonoscopy. This case illustrates that individual harm can be devastating. The USPSTF recommends against routine screening between ages 75 and 85 years, stating that there may be considerations supporting it in individual patients (C Grade) and against screening those $85+$ years. ${ }^{1}$

The article by Powell et al. ${ }^{2}$ does not deal with informed decision-making (which should be but is not an integral component of clinical preventive service recommendations and quality metrics ${ }^{3}$ ). Rather, Powell et al. ${ }^{2}$ ask an equally important related question: How often do clinicians offer colon cancer screening when the net population benefit approaches zero?

Among 1 million Veteran Administration Hospital patients $>50$ years who had one or more colon cancer screening procedures, over a quarter of fecal occult blood test (FOBT) tests and $14 \%$ of colonoscopies were potentially inappropriate. Appropriate colonoscopies were more likely to be
\end{abstract}

conducted at facilities where primary care providers were assigned responsibility for completing the CRC clinical reminder. These estimates - one may quibble that they are too low or too high, or generalizable to other settings - should remind all clinicians of the responsibility to optimize the benefit and minimize the harms of all clinical services we recommend to asymptomatic people. Perhaps it is also time to favor individualized clinical judgment over monolithic population screening algorithms that ignore individual clinician and patient values. ${ }^{3}$ At the very least, shared decision-making with patients who are fully informed of both the risks and benefits is needed. A better method of selecting patients at higher risk of disease would also help target those most likely to benefit from screening.

Conflict of Interest: The author has no conflicts of interest with this article.

Corresponding Author: David L. Hahn, MD MS; Wisconsin Research and Education Network (WREN), Department of Family Medicine, University of Wisconsin School of Medicine and Public Health, Madison, WI, USA (e-mail: dlhahn@wisc.edu).

\section{REFERENCES}

1. http://www.uspreventiveservicestaskforce.org/Page/Document/ RecommendationStatementFinal/colorectal-cancer-screening. Accessed $12 / 22 / 2014$.

2. Powell AA, Saini SD, Breitenstein MK, Noorbaloochi S, Cutting A, Fisher DA, Bloomfield HE, Halek K, Partin MR. Rates and correlates of potentially inappropriate colorectal cancer screening in the veterans health administration. J Gen Intern Med. (Article SPI \#3163).

3. Hahn DL. Public reporting needs reform! J Fam Pract. 2009;58:237-240. 